\title{
Research
}

Kornelis JJ van Hateren, Nanne Kleefstra, Marco H Blanker, Lielith J Ubink-Veltmaat, Klaas H Groenier, Sebastiaan T Houweling, Adriaan M Kamper, Klaas van der Meer and Henk JG Bilo

\section{Orthostatic hypotension, diabetes, and falling in older patients:}

\author{
a cross-sectional study
}

\begin{abstract}
\section{Background}

Although orthostatic hypotension $(\mathrm{OH})$ is more prevalent in old age, and in patients with diabetes, the prevalence of $\mathrm{OH}$ in older patients with type 2 diabetes mellitus is unknown.

\section{Aim}

To establish the prevalence of $\mathrm{OH}$, and its association with falling, in home-dwelling older participants with and without type 2 diabetes.
\end{abstract}

\section{Design and setting}

A cross-sectional study in primary care in the Netherlands.

\section{Method}

A total of 352 patients with type 2 diabetes, and 211 without participated in this study. $\mathrm{OH}$ was defined as a fall in blood pressure of at least $20 \mathrm{mmHg}$ systolic or $10 \mathrm{mmHg}$ diastolic after either 1 or 3 minutes in an upright position. Feelings of dizziness, light-headedness, or faintness during the standing period were documented as orthostatic complaints. Fall risk was assessed with a validated risk profile instrument

\section{Results}

The prevalence of $\mathrm{OH}$ was $28 \%(95 \% \mathrm{Cl}=24 \%$ to $33 \%)$ and $18 \%(95 \% \mathrm{Cl}=13 \%$ to $23 \%)$ in participants with and without type 2 diabetes respectively. $\mathrm{OH}$ was not related to falling. while the presence of orthostatic complaints in itself was associated with both previous fall incidents as well as a high fall risk, even after adjustment for $\mathrm{OH}$. The adjusted odds ratios were $1.65(95 \% \mathrm{Cl}=1.00$ to 2.72$)$ and $8.21(95 \%$ $\mathrm{Cl}=4.17$ to 16.19$)$, respectively.

\section{Conclusion}

$\mathrm{OH}$ is highly prevalent in home-dwelling older people with and without type 2 diabetes. Those with orthostatic complaints had an increased risk for falling, whereas those with $\mathrm{OH}$ were not.

\section{Keywords}

aged; diabetes mellitus type 2; falling; orthostatic hypotension; primary care.

\section{INTRODUCTION}

Orthostatic hypotension $(\mathrm{OH})$ is increasingly recognised as an important risk factor for cardiovascular disease and mortality. ${ }^{1-5}$ Many fall prevention programmes are based on the assumed association between $\mathrm{OH}$ and falling, although the evidence regarding this association is conflicting..$^{6-12}$ The reported prevalence of $\mathrm{OH}$ varies widely in literature, probably because its presence is influenced by many factors, including setting, age, definitions of $\mathrm{OH}$ medications used and comorbidity. $6.13,14$ In patients with diabetes, $\mathrm{OH}$ is considered to be a clinical manifestation of diabetic autonomic neuropathy. However, other risk factors for $\mathrm{OH}$, such as hypertension and cardiovascular disease, also cluster in patients with type 2 diabetes mellitus. The estimated prevalence of $\mathrm{OH}$ in homedwelling older people, aged $\geq 70$ years, is approximately $30 \%$. 1,15,16 Although $\mathrm{OH}$ is more prevalent in old age, ${ }^{6}$ and in patients with diabetes, ${ }^{17}$ the actual prevalence of $\mathrm{OH}$ in older patients with type 2 diabetes is unknown.

The primary objective of this crosssectional study was to establish the prevalence of $\mathrm{OH}$ in home-dwelling older patients with type 2 diabetes. Associated factors of $\mathrm{OH}$, and the prevalence of $\mathrm{OH}$ in participants without type 2 diabetes were

KJJ van Hateren, MD, GP in training: N Kleefstra MD, PhD, assistant professor, Diabetes Centre,

Isala Clinics, Zwolle, the Netherlands. MH Blanker, MD, PhD, GP: K van der Meer MD, PhD, GP, University of Groningen, University Medical Center Groningen, Department of General Practice, the Netherlands. LJ Ubink-Veltmaat MD, PhD, GP, General practice "t Veen', Hattem, the Netherlands. KH Groenier, Diabetes Centre, Isala Clinics, Zwolle the Netherlands ST Houweling, MD, PhD, GP, Langerhans Medical Research Group, Zwolle, the Netherlands. AM Kamper, MD, PhD, specialist internal medicine HJG Bilo, MD, PhD, specialist internal medicine, Diabetes Centre and Department of Internal also investigated. Because of the high fall rate in older people, especially in those with diabetes, ${ }^{18}$ and the conflicting evidence whether $\mathrm{OH}$ should be considered a risk factor for falling, the association of $\mathrm{OH}$ with fall incidents and fall risk was also investigated.

METHOD

\section{Study population}

Patients with type 2 diabetes participating in this cross-sectional observational study were recruited from 35 general practices, predominantly located in the north eastern region of the Netherlands. Recruitment and all study procedures took place between January 2009 and May 2010. Eligible patients with diabetes were either selected by practice nurses during the periodical diabetic check-up, or by the authors using the GPs' patients information systems. All participating nurses were visited and trained by the authors for trial procedures. The initial selection included patients with a diagnosis of type 2 diabetes, aged $\geq 70$ years, and the ability to follow the study protocol. Exclusion criteria were known autonomic dysfunction, neurodegenerative diseases, active malignancy, irregular pulse, and residing in a nursing home. Patients with irregular pulse were excluded because of the difficulty establishing 'real' $\mathrm{OH}$ in

Medicine, Isala Clinics, Zwolle, the Netherlands. Address for correspondence

Kornelis JJ van Hateren, Diabetes Centre, Isala Clinics. PO Box 10400, 8000 GK. Zwolle, The Netherlands.

E-mail: k.j.j.van.haterendisala.nl Submitted: 28 June 2011; Editor's response: 2 September 2011; final acceptance: 31 October 2011.

\section{CBritish Journal of General Practice}

This is the full-length article (published online 1 Oct 2012) of an abridged version published in print. Cite this article as: $\mathbf{B r} \mathbf{J}$ Gen Pract 2012; DOI: 10.3399/bjgp12X656838 


\section{How this fits in}

Although orthostatic hypotension $(\mathrm{OH})$ is more prevalent in old age, and in patients with diabetes, the prevalence of $\mathrm{OH}$ in older patients with type 2 diabetes is unknown. $\mathrm{OH}$ is also considered as an important risk factor for falling, however, the evidence regarding this association is conflicting. This study showed that $\mathrm{OH}$ is highly prevalent in home-dwelling older patients with type 2 diabetes. No association was found between falling and $\mathrm{OH}$. Remarkably, orthostatic complaints were associated with previous falling and high fall risk, even after adjustment for $\mathrm{OH}$ Perhaps, actively inquiring for orthostatic complaints, instead of measuring $\mathrm{OH}$, as part of the care for patients with type 2 diabetes and/or cardiovascular disease, may be a useful step.

these patients, due to the high variability of blood pressure. Although all practices were asked to participate in recruiting the control group, only a few practices were willing to do so. As a result, participants in the control group, with no history of diabetes, were selected from only seven of the 35 general practices. These participants were either selected during a consultation with the GP, or by the authors using the GPs' patient information systems. The same selection criteria as in the diabetes group were used. For the participants in the control group selected by using the patients information system, one additional criterion was used: a consultation with the GP in the last 6 months. This criterion was used to select a group that would be comparable to the patients who were selected during a consultation with the GP. Those who were selected using the GPs' patient information systems, were sent an invitation to participate in the study.

\section{Data collection}

Demographic characteristics, medical history, and medication use were assessed using a standard structured questionnaire. The risk of falling was measured using a self-administered validated risk profile developed to identify community-dwelling older people at high risk of recurrent falling. ${ }^{19}$ This risk profile assesses fall risk on the basis of previous fall incidents, body weight, functional limitations, handgrip strength, use of alcohol, presence of pets, level of education, and fear of falling. A high risk of falling was defined as a score of $\geq 10$ points on the risk profile and can be interpreted as a $50 \%$ chance of falling at least twice in the upcoming 3 years.

Measurements were performed by either the investigating authors or the practice nurses. Height, body weight, and blood pressure were measured in all participating participants. All participants were asked whether they had consumed a meal or drink within 1 and 2 hours, respectively, prior to the measurements. Blood pressure was measured following a standardised protocol, using a validated $A \& D$ digital blood pressure monitor, model UA-767 plus $30 .{ }^{20}$ Two supine measurements were performed after 5 minutes of rest, followed by two measurements after 1 minute standing and two measurements after 3 minutes standing. Mean values of the baseline, 1-minute and 3-minute measurements were calculated. During standing, the forearm of the participant was supported at heart level on an adjustable table or on the shoulder of the sitting investigator. ${ }^{21}$ The definition of $\mathrm{OH}$ was a fall in blood pressure of at least $20 \mathrm{mmHg}$ systolic or $10 \mathrm{mmHg}$ diastolic after either 1 or 3 minutes of standing after the participant changed from the supine to the upright position. ${ }^{22,23}$ After orthostatic testing, the participants were asked about feelings of dizziness, lightheadedness, or faintness during standing (orthostatic complaints).

\section{Statistical analyses}

Based on an estimated prevalence of $\mathrm{OH}$ of $30 \%$, the required sample size to obtain a $95 \%$ confidence interval (Cl) +/-5\% around the estimated prevalence, was 341. Therefore, the aim was to include 350 participants with type 2 diabetes. To enable a comparison of the results to those of participants without type 2 diabetes, the aim was to include approximately half the number of the study group: at least 150 participants.

First, univariate binary logistic regression analyses were performed to assess the association of the baseline characteristics with $\mathrm{OH}$ and orthostatic complaints. Multiple binary logistic regression analyses were performed to assess the association between $\mathrm{OH}$, orthostatic complaints, and type 2 diabetes. Model 1 was adjusted for age and sex. Model 2 was additionally adjusted for body mass index (BMI), a history of hypertension, previous macrovascular complications, supine systolic blood pressure, the number of antihypertensive medications used, and consumption of a meal or drink before blood pressure measurement.

Finally, the relationships between $\mathrm{OH}$ and orthostatic complaints, and previous 
fall incidents and high fall risk were investigated in four different models, in which fall incidents and high fall risk were the outcomevariables. Model 1 was adjusted for $\mathrm{OH}$, model 2 for orthostatic complaints, model 3 for $\mathrm{OH}$ and orthostatic complaints, and model 4 for symptomatic $\mathrm{OH}$, defined as $\mathrm{OH}$ combined with the presence of orthostatic complaints. All models were additionally adjusted for the following possible predictors of fall incidents and fall risk: age, sex, BMI, type 2 diabetes, previous macrovascular complications, and the number of antihypertensive medications used. Since body weight is part of the risk profile by which fall risk was defined, body mass index (BMI) was not included in the models for high fall risk. All analyses were performed with SPSS software (version 18). This study was registered at clinicaltrials. gov, NCT00807976. The manuscript was written based on the STrengthening the Reporting of OBservational studies in Epidemiology (STROBE) statement. ${ }^{24}$

\section{RESULTS}

\section{Study population}

A total of 352 patients with diabetes and 211 participants without type 2 diabetes participated in this study. The number of participants who were invited initially by either the practice nurses, GPs, or the authors, is unknown. This number is only known for the participants selected by the authors: $218(55 \%)$ of the 398 invited to participate actually took part in the study. The non-responders were older (78.6 versus 75.5 years, $P<0.0011$, but no significant sex difference between the responders and the non-responders was found $143.6 \%$ versus $35.6 \%$ males, $P=0.104)$.

Baseline characteristics and the results of the univariate regression analyses are presented in Table 1. There was a univariate association between both macrovascular complications and the total number of drugs and $\mathrm{OH}$ and orthostatic complaints. Experiencing orthostatic complaints was related to a higher risk of $\mathrm{OH}$. Higher blood pressure and not having consumed a meal or drink were associated with a higher prevalence of $\mathrm{OH}$, but not with the presence of orthostatic complaints. Female sex, hypertension, and the number of antihypertensive agents were only related to experiencing orthostatic complaints. A total of 169 out of the 553 (30.6\%) patients had fallen at least once in the previous year.

Type 2 diabetes and orthostatic hypotension

The prevalence of $\mathrm{OH}$ was $28 \% 195 \% \mathrm{C}$

\section{Table 1. Baseline characteristics and results of univariate logistic regression analyses with orthostatic}

hypotension and orthostatic complaints as dependent variables, $(n=563)$

\begin{tabular}{|c|c|c|c|}
\hline \multirow[b]{2}{*}{ Characteristic } & \multirow[b]{2}{*}{$n^{a}$} & \multicolumn{2}{|c|}{ OR $(95 \% \mathrm{CI})$} \\
\hline & & $\mathrm{OH}$ & Orthostatic complaints \\
\hline \multicolumn{4}{|l|}{ Demographics } \\
\hline Median age, years (IQR) & $75(72-79)$ & 0.99 (0.95 to 1.03 ) & 0.99 (0.95 to 1.05$)$ \\
\hline Male sex $(\%)$ & $265 / 563(47.1)$ & $1.06(0.72$ to 1.56$)$ & $0.56(0.35$ to 0.91$)$ \\
\hline Mean body mass index, $\mathrm{kg} / \mathrm{m}^{2}$ (SD) & $28.0(4.2)$ & 0.97 (0.93 to 1.02$)$ & $1.00(0.95$ to 1.06$)$ \\
\hline Type 2 diabetes mellitus (\%) & $352 / 563$ (62.5) & 1.87 (1.22 to 2.85$)$ & $2.16(1.27$ to 3.69$)$ \\
\hline Median duration of diabetes, years (IQR) & $6(4-10)$ & 1.00 (0.96 to 1.05$)$ & 1.00 (0.96 to 1.05$)$ \\
\hline Hypertension (\%) & 438/563 (77.8) & 1.37 (0.84 to 2.24$)$ & $2.11(1.08$ to 4.11$)$ \\
\hline Macrovascular complications (\%) & $175 / 563(31.1)$ & $1.71(1.15$ to 2.56$)$ & $2.13(1.33$ to 3.41$)$ \\
\hline Family history of CVD (\%) & $141 / 563(25.0)$ & 1.09 (0.70 to 1.69$)$ & 1.05 (0.62 to 1.79 ) \\
\hline \multicolumn{4}{|l|}{ Measurements } \\
\hline Consumption meal or drink (\%) & $394 / 558(70.6)$ & $0.40(0.27$ to 0.60$)$ & $0.82(0.50$ to 1.35$)$ \\
\hline Mean systolic BP lying, mmHg (SD) & $142.1(20.5)$ & $1.31(1.19$ to 1.44$)$ & 0.89 (0.79 to 1.00$)$ \\
\hline Mean diastolic BP lying, mmHg (SD) & $76.1(9.9)$ & 1.33 (1.09 to 1.62$)$ & 0.85 (0.67 to 1.08$)$ \\
\hline Mean pulse frequency (SD) & $67.0(10.8)$ & $0.99(0.97$ to 1.01$)$ & 1.00 (0.98 to 1.02$)$ \\
\hline Orthostatic complaints (\%) & $85 / 563(15.1)$ & 2.02 (1.23 to 3.29$)$ & NA \\
\hline \multicolumn{4}{|l|}{ Medication } \\
\hline Median number of pharmacological agents (IQR) & $5(3-6)$ & 1.12 (1.04 to 1.20$)$ & 1.17 (1.08 to 1.27$)$ \\
\hline Median number of antihypertensive agents (IQR) & $2(0-3)$ & 1.14 (0.99 to 1.32$)$ & $1.19(1.01$ to 1.41$)$ \\
\hline Antihypertensive medication & $418 / 563(74.2)$ & $1.39(0.88$ to 2.21$)$ & 1.74 (0.96 to 3.15$)$ \\
\hline
\end{tabular}


Table 2. Adjusted ORs for the effects of clinical variables on the risk of orthostatic hypotension and orthostatic complaints

\begin{tabular}{|c|c|c|c|c|}
\hline \multirow[b]{2}{*}{ Variable } & \multicolumn{2}{|c|}{ Orthostatic hypotension, OR $(95 \% \mathrm{Cl})$} & \multicolumn{2}{|c|}{ Orthostatic complaints, OR (95\% Cl) } \\
\hline & Model 1 & Model 2 & Model 1 & Model 2 \\
\hline Diabetes: diabetes versus control & $1.89(1.23$ to 2.90$)$ & 1.89 (1.16 to 3.08$)$ & $2.34(1.36$ to 4.02$)$ & 2.08 (1.17 to 3.72 ) \\
\hline Age & 0.99 (0.94 to 1.03$)$ & 0.95 (0.91 to 1.00$)$ & 0.98 (0.93 to 1.04$)$ & 0.98 (0.93 to 1.03 ) \\
\hline Sex: male versus female & 1.00 (0.68 to 1.48$)$ & 0.97 (0.63 to 1.50$)$ & 0.52 (0.32 to 0.85 ) & 0.38 (0.23 to 0.65$)$ \\
\hline BMI & - & $0.95(0.90$ to 1.01$)$ & - & 0.96 (0.91 to 1.03 ) \\
\hline Hypertension & - & 0.85 (0.42 to 1.69$)$ & - & $1 . .78(0.75$ to 4.24$)$ \\
\hline Macrovascular complications & - & 2.14 (1.33 to 3.45$)$ & - & 2.29 (1.33 to 3.92 ) \\
\hline Systolic blood pressure & - & $1.33(1.20$ to 1.48$)$ & - & 0.87 (0.76 to 0.98 ) \\
\hline Antihypertensive medication & - & $1.03(0.84$ to 1.27$)$ & - & $0.93(0.74$ to 1.19$)$ \\
\hline Consumption of meal or drink & - & 0.46 (0.30 to 0.72$)$ & - & 0.76 (0.45 to 1.29$)$ \\
\hline
\end{tabular}

The ORs for systolic blood pressure refer to a pressure increase of $10 \mathrm{mmHg}$. The ORs can be interpreted as a measure of the association of the various variables to either orthostatic hypotension or orthostatic complaints (the dependent variables). $B M I=$ body mass index. $O R=$ odds ratio.

$=24 \%$ to $33 \%)$ and $18 \%(95 \% \mathrm{Cl}=13 \%$ to $23 \%$ ) in participants with and without type 2 diabetes, respectively. The results from the multivariate logistic regression analyses show that the association between type 2 diabetes and $\mathrm{OH}$ is independent from other clinical variables (Table 2). In these models, a history of macrovascular complications, higher supine systolic blood pressure, and no consumption of a meal or drink before measurements were also independently associated with a higher risk of $\mathrm{OH}$. The prevalence of orthostatic complaints was $18 \%(95 \% \mathrm{Cl}=15 \%$ to $23 \%)$ and $10 \%$

Table 3. Adjusted ORs for the effect of clinical variables on the risk of previous fall incidents and high fall risk

\begin{tabular}{|c|c|c|c|c|}
\hline \multirow[b]{2}{*}{ Variable } & \multicolumn{4}{|c|}{ Previous fall incidents as the dependent variable, OR (95\% CI) } \\
\hline & Model 1 & Model 2 & Model 3 & Model 4 \\
\hline $\mathrm{OH}$ & $0.94(0.61$ to 1.46$)$ & - & $0.90(0.58$ to 1.40$)$ & - \\
\hline Orthostatic complaints & - & $1.63(0.99$ to 2.68$)$ & $1.65(1.00$ to 2.72$)$ & - \\
\hline Symptomatic $\mathrm{OH}$ & - & - & - & 1.99 (0.93 to 4.23) \\
\hline Age & 1.02 (0.98 to 1.07 ) & 1.03 (0.98 to 1.07$)$ & 1.02 (0.98 to 1.07$)$ & 1.03 (0.98 to 1.07 ) \\
\hline Sex: male versus female & 0.50 (0.34 to 0.75$)$ & 0.53 (0.36 to 0.79$)$ & $0.53(0.36$ to 0.78$)$ & 0.53 (0.36 to 0.78$)$ \\
\hline $\mathrm{BMI}$ & 0.98 (0.93 to 1.03 ) & 0.98 (0.94 to 1.03$)$ & 0.98 (0.94 to 1.03$)$ & 0.98 (0.94 to 1.03$)$ \\
\hline Diabetes: diabetes versus control & 1.08 (0.72 to 1.62$)$ & $1.02(0.68$ to 1.54$)$ & 1.03 (0.68 to 1.55$)$ & 1.06 (0.71 to 1.59$)$ \\
\hline Macrovascular complications & 1.06 (0.68 to 1.64$)$ & $0.99(0.64$ to 1.54$)$ & $1.00(0.64$ to 1.56$)$ & $0.99(0.64$ to 1.54$)$ \\
\hline \multirow[t]{3}{*}{ Antihypertensive medication } & 1.07 (0.92 to 1.25 ) & 1.07 (0.91 to 1.25$)$ & 1.07 (0.92 to 1.25 ) & 1.07 (0.92 to 1.25$)$ \\
\hline & \multicolumn{4}{|c|}{ High fall risk as the dependent variable, OR (95\% CI) } \\
\hline & Model 1 & Model 2 & Model 3 & Model 4 \\
\hline Orthostatic complaints & - & 7.77 (3.98 to 15.17 ) & $8.21(4.17$ to 16.19$)$ & - \\
\hline Symptomatic $\mathrm{OH}$ & - & - & - & 2.87 (1.09 to 7.55 ) \\
\hline Age & $1.07(1.01$ to 1.14$)$ & $1.09(1.02$ to 1.16$)$ & $1.09(1.02$ to 1.16$)$ & $1.07(1.01$ to 1.14$)$ \\
\hline Sex, male versus female & 0.47 (0.24 to 0.92$)$ & $0.61(0.30$ to 1.23$)$ & 0.59 (0.29 to 1.20$)$ & 0.53 (0.27 to 1.04$)$ \\
\hline Diabetes: diabetes versus control & 1.75 (0.83 to 3.68$)$ & 1.38 (0.64 to 2.98$)$ & $1.39(0.65$ to 3.01$)$ & 1.69 (0.80 to 3.56$)$ \\
\hline Macrovascular complications & $1.61(0.82$ to 3.17$)$ & $1.16(0.57$ to 2.39$)$ & $1.24(0.60$ to 2.57$)$ & 1.39 (0.70 to 2.77$)$ \\
\hline Antihypertensive medication & 1.20 (0.94 to 1.54$)$ & 1.21 (0.94 to 1.57$)$ & 1.21 (0.94 to 1.57 ) & 1.21 (0.94 to 1.55$)$ \\
\hline
\end{tabular}

Model 1 was adjusted for $\mathrm{OH}$, model 2 for orthostatic complaints, model 3 for $\mathrm{OH}$ and orthostatic complaints, and model 4 for symptomatic orthostatic hypotension. All models were additionally adjusted for the following possible predictors of fall incidents: age, sex, BMI, type 2 diabetes, previous macrovascular complications, and the number of antihypertensive medications used. BMI was not included in the models with high fall risk as the dependent variable, since body weight is used in the risk profile by which high fall risk was defined. The ORs can be interpreted as a measure of the association of the various variables to either previous fall incidents or high fall risk Ithe dependent variables). $\mathrm{BMI}=$ body mass index. $\mathrm{OH}=$ orthostatic hypotension. $\mathrm{OR}=$ odds ratio. 
$(95 \% \mathrm{Cl}=6 \%$ to $14 \%)$ in participants with and without type 2 diabetes, respectively. In multivariate analyses, the association between orthostatic complaints and type 2 diabetes was confirmed. Female sex, a history of macrovascular complications, and lower supine systolic blood pressure increased the risk of orthostatic complaints.

\section{Fall incidents and fall risk}

Table 3 presents the multivariate regression analyses with previous fall incidents and high fall risk as the dependent variables. $\mathrm{OH}$ was not related to previous fall incidents and high fall risk, in both univariate (data not shown) and multivariate analyses. The unadjusted odds ratios (ORs) of orthostatic complaints for fall incidents and high fall risk were $1.79(95 \% \mathrm{Cl}=1.11$ to 2.88$)$ and 8.60 (4.57 to 16.19), respectively. In multivariate analyses, the ORs were 1.63 $195 \% \mathrm{Cl}=0.99$ to 2.68$)$ and $7.77(95 \% \mathrm{Cl}=$ 3.98 to 15.17). After additionally adjusting for $\mathrm{OH}$, orthostatic complaints remained associated with previous fall incidents and a high fall risk. Female sex was independently related to previous fall incidents. Higher age was associated with high fall risk only.

\section{DISCUSSION}

\section{Summary}

The prevalence of $\mathrm{OH}$ in older homedwelling patients with type 2 diabetes was $28 \%$, which was significantly higher than the prevalence of $18 \%$ in the patients without type 2 diabetes. Besides type 2 diabetes, there were independent associations with a history of macrovascular complications, higher systolic blood pressure, and no consumption of a meal or drink before orthostatic testing. $\mathrm{OH}$ was not related to either previous fall incidents or a high fall risk. Only the presence of orthostatic complaints was associated with more fall incidents and an increased risk of falling, even after adjustment for $\mathrm{OH}$. Orthostatic complaints were more prevalent in patients with type 2 diabetes or cardiovascular disease, and in females.

\section{Strengths and limitations}

The main limitation of the study is potential selection bias. Participants were either selected by practice nurses during the periodical diabetic check-up, or by the authors using the GPs' patient information systems. Since the majority of the patients in the diabetes group were selected by practice nurses $(77 \%)$, and the majority of the control group by the authors, this may have led to a selection bias. However, baseline characteristics of patients with type 2 diabetes did not differ between those recruited by the practice nurses and those recruited by the authors (data not presented). Therefore, this gives some reassurance that differences between the nurses and authors have not led to an important selection bias. It is also possible that the patients who were willing to participate had some characteristics that could not be adjusted for in the analyses. Unfortunately, data of the non-responders were only known for the participants selected by the authors. Since the responders in this study were younger than the non-responders, the results on prevalence of $\mathrm{OH}$ may be an underestimation. Differences between the seven general practices, in which the control group was recruited, and the other 28 practices may also have led to selection bias. However, the characteristics of patients with type 2 diabetes who were selected in the seven practices were not different from the patients in the other 28 practices (data not presented). Furthermore, patients with an irregular pulse were excluded from the study. Therefore, the results are not applicable to patients with an irregular pulse/atrial fibrillation.

Another limitation of this study may be the possibility of recall bias. As fall incidents were assessed retrospectively, it is very likely that the actual number of fall incidents was higher. Finally, there was a poor correlation between $\mathrm{OH}$ and orthostatic complaints. Of the 137 patients with $\mathrm{OH}$, only 31 patients had typical orthostatic complaints. Perhaps differences in the definition of $\mathrm{OH}$ may explain the poor correlation between $\mathrm{OH}$ and orthostatic complaints. However, the correlation between $\mathrm{OH}$ and orthostatic complaints was not different for various definitions of $\mathrm{OH}$ in the current study (data not presented). The majority of studies, such as the study by Rutan et al, ${ }^{6}$ did not describe either the number of patients with $\mathrm{OH}$ and complaints, nor the number of patients experiencing complaints without measuring $\mathrm{OH}$, making it difficult to compare the poor correlation found in the current study to those studies. A recent study using continuous non-invasive orthostatic blood pressure measurements showed that only initial orthostatic hypotension (during the first 15 seconds) was related to orthostatic complaints and falls, whereas this relationship was not found for orthostatic hypotension after 3 minutes. ${ }^{25}$ This could also be the explanation for the poor correlation between $\mathrm{OH}$ and complaints/ falls in the current study. Unfortunately, blood pressure was not measured within the first seconds upon standing in this study. 
This study has some notable strengths. Firstly, the mean of two blood pressure measurements was calculated at baseline, after 1 minute of standing, and after 3 minutes of standing. This allowed for correction of the imprecision inherent to a single blood pressure measurement. Secondly, all measurements were performed using the same validated automatic blood pressure monitoring device. Thirdly, unlike many other studies data were collected on consumption of meals or drinks before orthostatic testing.

\section{Comparison with existing literature}

In previous reports, the prevalence of $\mathrm{OH}$ in home-dwelling older people, aged $\geq 70$ years, was estimated to be approximately $30 \%$ in the general population. 1,15,16 This is comparable to the prevalence in patients with type 2 diabetes observed in the current study. However, the prevalence in this study's control group was much lower. Higher mean age, lower $\mathrm{BMI}$, and higher blood pressure may be the explanations for the higher prevalence of $\mathrm{OH}$ observed in previous studies. ${ }^{1,15,16}$ Only one previous population-based study by Wu et al specifically investigated the prevalence of $\mathrm{OH}$ in type 2 diabetes before, and reported a prevalence comparable to this study, namely $25.5 \% .^{17}$ In $\mathrm{Wu}$ et al's study, mean age was lower and fewer patients were on antihypertensive medication. All measurements were performed between 8.00 and $10.00 \mathrm{am}$ in the morning, unlike in the current study in which measurements were performed throughout the day. Since the prevalence of $\mathrm{OH}$ is higher when measured in the morning, especially before breakfast, this may have caused an underestimation of the prevalence of $\mathrm{OH}$ in the current study. ${ }^{26}$ The associations observed between $\mathrm{OH}$ and macrovascular complications, higher systolic blood pressure, and not having consumed a meal or drink before testing confirm data from previous studies. 1,6,17,26
A prospective study on fall risk showed that withdrawal of cardiovascular drugs led to lower fall risk and a reduction in $\mathrm{OH} .{ }^{27,28}$ Although a relationship between $\mathrm{OH}$ and falling was suggested in this study, causality was not proven. Observational studies show conflicting evidence regarding the association between $\mathrm{OH}$ and fall incidents. ${ }^{6-12}$ Except for the study by Rutan et al, ${ }^{6}$ all other studies, which reported a positive association between falling and $\mathrm{OH}$, were performed in nursing homes or homes for older people..$^{7-10}$ In the community-based study by Rutan et $a$, orthostatic testing was only performed after 3 minutes of standing. The age- and clinic-adjusted $\mathrm{OR}$ of $\mathrm{OH}$ for frequent falls was $1.52(95 \% \mathrm{Cl}=1.04$ to 2.22$)$ in Rutan et al's study. ${ }^{6}$ The relationship between $\mathrm{OH}$ and fall incidents is probably influenced by many factors, including study population (such as, nursing home versus communitydwelling older people) and definition of $\mathrm{OH}$ (such as, blood pressure drop after 1 minute versus blood pressure drop after 1 or 3 minutes). Furthermore, in contrast to the current study that assessed fall incidents retrospectively, previous studies that showed positive associations had a prospective study design. However, based on the current study's results it can be hypothesised that it is not $\mathrm{OH}$, but the presence of orthostatic complaints that is predictive of previous fall incidents and high fall risk in a home-dwelling older population.

\section{Implications for practice and research}

This study shows that $\mathrm{OH}$ is highly prevalent in older patients with and without type 2 diabetes. The results suggest that falling is only related to orthostatic complaints, and not to $\mathrm{OH}$. Confirmation in other studies is necessary, and if confirmed, it may be as simple as just asking some questions instead of following a time-consuming protocol to select those patients with an increased risk of falling.

\section{Provenance}

Freely submitted; externally peer reviewed.

\section{Competing interests}

The authors have declared no competing interests.

\section{Acknowledgements}

The authors would like to thank all 35 participating general practices.

\section{Discuss this article}

Contribute and read comments about this article on the Discussion Forum: http://www.rcgp.org.uk/bjgp-discuss 


\section{REFERENCES}

1. Luukinen H, Koski K, Laippala P, Kivelä SL. Prognosis of diastolic and systolic $\mathrm{OH}$ in older persons. Arch Intern Med 1999; 159: 273-280.

2. Luukinen $\mathrm{H}$, Airaksinen KEJ. Orthostatic hypotension predicts vascular death in older diabetic patients. Diabetes Res Clin Pract 2005; 67: 163-166.

3. Rose KM, Eigenbrodt ML, Biga RL, et al. Orthostatic hypotension predicts mortality in middle-aged adults. The Atherosclerosis Risk in Communities (ARIC) study. Circulation 2006; 114: 630-636.

4. Rose KM, Tyroler HA, Nardo CJ, et al. Orthostatic hypotension and the incidence of coronary heart disease: the Atherosclerosis Risk in Communities Study. Am J Hypertens 2000; 13: 571-578.

5. Eigenbrodt ML, Rose KM, Couper DJ, et al. Orthostatic hypotension as a risk factor for stroke. The Atherosclerosis Risk in Communities (ARIC) study, 19871996. Stroke 2000; 31: 2307-2313.

6. Rutan GH, Hermanson B, Bild DE, et al. Orthostatic hypotension in older adults. The cardiovascular health study. CHS Collaborative Research Group. Hypertension 1992; 19: 508-519.

7. Ooi WL, Hossain M, Lipsitz LA. The association between orthostatic hypotension and recurrent falls in nursing home residents. Am J Med 2000; 108: 106-111.

8. Tinetti ME, Williams TF, Mayewski R. Fall risk index for elderly patients based on number of chronic disabilities. Am J Med 1986; 80: 429-434.

9. Rubenstein LZ, Josephson KR, Robbins AS. Falls in the nursing home. Ann Intern Med 1994; 121: 442-451.

10. Graafmans WC, Ooms ME, Hofstee HM, et al. Falls in the elderly: a prospective study of risk factors and risk profiles. Am J Epidemiol 1996; 143: 1129-1136.

11. Liu BA, Topper AK, Reeves RA, et al. Falls among older people: relationship to medication use and orthostatic hypotension. J Am Geriatr Soc 1995; 43: 1141 1145

12. Maurer MS, Cohen S, Cheng HC. The degree and timing of orthostatic blood pressure changes in relation to falls in nursing home residents. J Am Med Dir Assoc 2004; 5: 233-238.

13. Low PA. Prevalence of orthostatic hypotension. Clin Auton Res 2008; 18[suppl1]: 8-13.

14. Masaki KH, Schatz IJ, Burchfiel CM, et al. Orthostatic hypotension predicts mortality in elderly men: the Honolulu Heart Program. Circulation 1998; 98: 2290-2295.

15. Tilvis RS, Hakala SM, Valvanne J, Erkinjuntti T. Postural hypotension and dizziness in a general aged population: a four-year follow-up of the Helsink
Aging Study. J Am Geriatr Soc 1996; 44: 809-814.

16. Hiitola $\mathrm{P}$, Enlund $\mathrm{H}$, Kettunen $\mathrm{R}$, et al. Postural changes in blood pressure and the prevalence of orthostatic hypotension among home-dwelling elderly aged

75 years or older. J Hum Hypertens 2009; 23: 33-39.

17. Wu JS, Yang YC, Lu FH, et al. Population-based study on the prevalence and risk factors of orthostatic hypotension in subjects with pre-diabetes and diabetes mellitus. Diabetes Care 2009; 32: 69-74.

18. Tilling LM, Darawil K, Britton M. Falls as a complication of diabetes mellitus in older people. J Diabetes Complications 2006; 20: 158-162.

19. Pluijm SMF, Smit JH, Tromp EAM, et al. A risk profile for identifying communitydwelling elderly with a high risk of recurrent falling: results of a 3-year prospective study. Osteoporos Int 2006; 17: 417-425.

20. Verdecchia P, Angeli F, Poeta F, et al. Validation of the A\&D UA774 (UA-767Plus) device for self measurement of blood pressure. Blood Press Monit 2004: 9: 225-229

21. Mariotti G, Alli C, Avanzini F, et al. Arm position as a source of error in blood pressure measurement. Cluin Cardiol 1987; 10: 591-593.

22. Anonymous. Consensus statement on the definition of orthostatic hypotension, pure autonomic failure, and multiple system atrophy. The Consensus Committee of the American Autonomic Society and the American Academy of Neurology. Neurology 1996; 46: 1470.

23. Lahrmann $\mathrm{H}$, Cortelli $\mathrm{P}$, Hilz $\mathrm{M}$, et al. EFNS guidelines on the diagnosis and management of orthostatic hypotension. Eur J Neurol 2006; 13: 930-936.

24. von Elm E, Altman DG, Egger M, et al. The Strengthening the Reporting of Observational Studies in Epidemiology (STROBE) Statement: Guidelines for Reporting Observational Studies. PLoS Med 2007; 4(10): e296.

25. Romero-Ortuno R, Cogan L, Foran T, Kenny RA, Fan CW. Continuous noninvasive orthostatic blood pressure measurements and their relationship with orthostatic intolerance, falls, and frailty in older people. J Am Geriatr Soc 2011; 59: 655-665

26. Ooi WL, Barrett S, Hossain M, Kelley-Gagnon M, Lipsitz LA. Patterns of orthostatic blood pressure change and their clinical correlates in a frail, elderly population. JAMA 1997; 277: 1299-1304.

27. van der Velde N, Stricker BH, Pols HA, Van der Cammen TJ. Risk of falls after withdrawal of fall-risk-increasing drugs: a prospective cohort study. $\mathrm{Br} J$ Clin Pharmacol 2007; 63: 232-237.

28. van der Velde N, Van den Meiracker AH, Pols HA, et al. Withdrawal of fall-risk increasing drugs in older persons: effect on tilt-table test outcomes. J Am Geriatr Soc 2007: 55: 734-739. 